$\begin{gathered}\text { Revista do Departamento de Geografia } \\ \text { Universidade de São Paulo } \\ \text { www.revistas.usp.br/rdg }\end{gathered}$
Vevista do Departamento de Geografia USP
ISSN 2236-2878

\title{
Potencialidade do Índice de Posição Topográfica no Mapeamento Pedológico Preditivo em uma Sub-Bacia do Rio Capricórnio-PR
}

\author{
Potentiality of The Topographic Position Index in The \\ Predictive Pedological Mapping in a Capricornio-PR River Subbasin
}

Recebido (Received): 07/04/2017 DOI: $10.11606 /$ rdg.v34io.130727

Aceito (Accepted): 31/08/2017

\author{
Alexei Nowatzki \\ Universidade Federal do Paraná \\ nowatzki.a@gmail.com \\ Leonardo José Cordeiro Santos \\ Universidade Federal do Paraná \\ santos.ufpr@gmail.com \\ Claudinei Taborda da Silveira \\ Universidade Federal do Paraná \\ claudineits@ufpr.br
}

\begin{abstract}
Resumo: Os solos do noroeste do estado do Paraná apresentam grande intensidade de processos erosivos em função de suas características físico-naturais, sendo que esses processos se iniciam em Argissolos, localizados nos terços inferiores das vertentes e evoluem remontantemente em direção aos Latossolos. O Mapeamento Digital de Solos (MDS) pode auxiliar no detalhamento dos mapas pedológicos existentes, pois, a partir de atributos topográficos extraídos do Modelo Digital do Terreno (MDT), pode-se predizer a ocorrência das classes de solos. O atributo Índice de Posição Topográfica (IPT) compartimenta a vertente em porções de terços inferiores, mais próximas dos fundos de vales, e dos terços superiores, próximos dos divisores de águas. Aplicado na sub-bacia do rio Capricórnio, esse índice mostrou grande representatividade na distribuição dos solos estudados. Por tabulação cruzada, o IPT foi combinado com o atributo topográfico clinografia permitindo definir três grupos: Latossolos, nos terços superiores e médios das vertentes, com baixas declividades; Argissolos, nos terços inferiores, com declives mais acentuados; e o terceiro, que é uma transição entre os dois grupos. Pelo MDS, a distribuição dos Argissolos na bacia foi de $14,7 \%$ do total da área. Os Latossolos se estenderam na maior parte da bacia, com $76,1 \%$. Já as porções com solos de transição ocuparam 9,2 \%. Destaca-se, assim, a importância dos MDS, uma vez que permitem detalhar mapas menos detalhados.
\end{abstract}

Palavras-Chave: Mapeamento Digital de Solos; Modelo Digital do Terreno; Tabulação Cruzada; Cartografia pedológica.

\begin{abstract}
The soils of the northwest of the state of Paraná have a high intensity of erosive processes due to its physical-natural characteristics, and these processes initiate in the Ultisols, located in the lower thirds of the slope and evolve reassembling towards the Oxisols. Digital Soil Mapping (DSM) can assist the detailing of existing pedological maps, because the topographic attributes extracted from the Digital Terrain Model (DTM) can predict soil classes. The attribute Topographic Position Index (TPI) compartmentalizes the slope in portions of lower thirds, closer to the bottom of valleys, and the upper thirds, near the water partings. Applied in the sub-basin of the Capricórnio River, this index showed great representativeness in the distribution of the studied soils. By cross-tabulation, the TPI was combined with the topographic attribute slope allowing to define three groups: Oxisols, in the upper and middle thirds of the slopes, with gentle slopes; Ultisols, in the lower thirds, of steeper slopes; and the third, which is a transition between both groups. By the DSM, the distribution of the Ultisols in the basin was $14,7 \%$ of the total area. Oxisols extended in most of the basin, with $76,1 \%$. The portions with transitional soils occupied 9,2\%. The importance of DSM is highlighted, since it can detail more precisely maps less detailed.
\end{abstract}

Keywords: Digital Soil Mapping; Digital Terrain Model; Cross-tabulation; Pedological Cartography 


\section{INTRODUÇÃO}

A região noroeste do estado do Paraná se distingue por apresentar processos acelerados de erosão hídrica a partir da década de 1950, sobretudo com a presença significativa de ravinas e voçorocas, pois não se teve a preocupação de se respeitar as limitações físicas (geologia, relevo, solos e o clima) e ecológicas no processo de ocupação, tanto com a inserção da agricultura quando na instalação dos centros urbanos (MANGUEIRA et al., 2013; SANTOS; WESTPHALEN, 2014).

Aliado às condições de uso do solo, impostas pela nova forma de ocupação humana, os processos erosivos se intensificaram em função das características físico-naturais dos solos, principalmente pela influência litológica do Grupo Caiuá na sua textura. Inserido no Terceiro Planalto Paranaense, esse grupo apresenta um conjunto de rochas sedimentares de deposição eólica do período Cretáceo que recobrem a região noroeste do Paraná (GASPARETTO et al., 2001; FERNANDES et al., 2012). Nakashima (1999) destaca que na região o relevo se apresenta uniforme e suave, com planaltos escalonados, inclinados levemente em direção ao vale do rio Paraná. Os solos são predominantemente espessos, em geral com textura variando de muito arenosa a médiaargilosa, o que the confere elevada suscetibilidade aos processos erosivos.

O uso cada vez mais intensivo do solo, associado à falta de manejo adequado, resulta na sua degradação, sobretudo naqueles mais suscetíveis à erosão. Desse modo, por apresentarem informações básicas sobre esse recurso natural e sua distribuição na paisagem, os mapeamentos são fundamentais para auxiliar no manejo sustentável dos solos. Apesar da relevância e da demanda, cabe destacar que existe uma grande carência de informações e de levantamentos mais detalhados sobre os solos do Brasil (DALMOLIN; TEN CATEN, 2015).

Conforme o mapeamento pedológico realizado pela EMBRAPA (2007) na escala 1:250.000, no noroeste do estado, ocorrem dois tipos principais de solos: Latossolos (L) e Argissolos (P). Em relação ao comportamento físico e hídrico desses dois solos, com o aparecimento do horizonte $B$ textural (Bt) característico dos Argissolos - que modifica as dinâmicas hídricas -, a drenagem passa de vertical e profunda nos Latossolos, localizados a montante, para lateral e subsuperficial quando aparece o horizonte $\mathrm{Bt}$ a jusante. A camada arenosa pouco resistente que constitui o horizonte $\mathrm{E}$, acima do Bt, é mais suscetível à erosão linear (ravinas e voçorocas) e à erosão laminar (SALOMÃO, 1994; SANTOS, 2000).

Nakashima (op. cit.) descreveu e mapeou os principais sistemas pedológicos dessa região, permitindo uma visão da distribuição desses sistemas e suas correlações com o relevo e com as feições erosivas. O autor destacou que os processos erosivos são agressivos nos terços inferiores das vertentes, onde os Argissolos se localizam, e as erosões desenvolvidas nessa área evoluem em direção à montante (predominância dos Latossolos). Desse modo, saber com maior detalhe onde são os limites desses dois solos na vertente pode contribuir para o emprego de técnicas de manejo, evitando, deste modo, que mais processos erosivos se intensifiquem no local.

Os mapeamentos tradicionais de solos em escalas grandes, precisam necessariamente de um controle adequado de campo para ter resultados mais precisos e confiáveis e muitas vezes este controle acaba tendo elevado custo financeiro, bem como um longo tempo necessário para se realizar tais levantamentos. Além desses custos, leva-se bastante tempo para elaboração de mapas com escalas de maior detalhamento, utilizando métodos convencionais de mapeamento (COELHO, 2010; NOWATZKI, 2013).

Desse modo, para uma melhor representação cartográfica da distribuição dos solos, pode-se utilizar um mapeamento preditivo, definido por McBratney et al. (2003) como Mapeamento Digital de Solos (MDS), considerado um novo paradigma da pedologia, em que inovações tecnológicas em equipamentos, modelos estatísticos e matemáticos são aplicados.

Esse método baseia-se na combinação de parâmetros geomorfométricos denominados atributos topográficos (MOORE et al., 1993). Esses atributos são calculados diretamente do Modelo Digital do Terreno (MDT) e, quando combinados, geram compartimentos que podem predizer a ocorrência de um determinado tipo de solo na paisagem (MOORE et al., 1993; McBRATNEY et al., 2000; McBRATNEY et al., 2003; SILVEIRA et al., 2013; NOWATZKI; SANTOS, 2014). 
O MDS auxilia na definição dos limites das unidades pedológicas, de acordo com um modelo geomorfológico, e tem mostrado potencial para a predição de ocorrência dos tipos de solos. Essa técnica auxiliar em levantamentos de solos constitui-se uma evolução no entendimento das relações pedologia-geomorfologia e, consequentemente, uma ferramenta importante para identificar e mapear áreas de solos homogêneos (SIRTOLI et al., 2008).

Segundo Teske (2015), os levantamentos pedológicos convencionais são a forma mais comum de mapeamento e, em muitos casos, a única maneira pela qual as relações solo-paisagem são documentadas. Esses levantamentos são importante fonte de informações sobre a distribuição e caracterização dos solos e a maioria é elaborada a partir da observação no campo e do estabelecimento de relações entre os solos e as características da paisagem. As técnicas do MDS da mesma forma, consistem no estabelecimento dessas relações; porém, isso é feito de forma mais quantitativa do que nos mapas tradicionais. Para isso, utilizam-se modelos numéricos ou estatísticos para inferir as variações espaciais dos solos, a partir de mapas já existentes, de observações em campo ou de variáveis ambientais correlacionadas.

Para Lagacherie e Voltz (2000), uma das possibilidades do MDS é utilizar a modelagem para extrapolar os limites das classes de solos mapeadas digitalmente para áreas adjacentes e não mapeadas, no caso daquelas com o mesmo padrão geomorfológico e geológico, resultando em ganho de informações geradas previamente em áreas de referência.

O MDS, assim como o levantamento tradicional, faz uso de informações coletadas ou disponíveis em pontos de observação de solos. Esses dados são utilizados para ajustar um modelo quantitativo com variáveis relativas às condições do ambiente, nos mesmos locais, e o modelo ajustado é depois empregado para predizer propriedades do solo ou classes de solos para o restante da área (LAGACHERIE, 2008). Da mesma forma, Dalmolin e Ten Caten (2015) destacam que a produção de mapas de classes e atributos com maior nível de detalhamento só será possível com a utilização de geotecnologias combinadas com dados coletados no campo.

Tendo em vista tais considerações, os objetivos do trabalho são: 1) estabelecer as relações entre a distribuição dos solos com as classes dos atributos topográficos índice de posição topográfica (IPT) e clinografia; 2) formular regras de classificação para a identificação das unidades de mapeamento; 3) realizar a confecção do mapa digital de solos da área de estudo na escala 1:50.000; e 4) compará-lo com o mapeamento preexistente (EMBRAPA, 2007), feito na escala 1:250.000.

A área de estudo (Figura 1) localiza-se no noroeste do estado do Paraná, entre os municípios de Cruzeiro do Oeste e Tapejara e é uma sub-bacia hidrográfica do rio Capricórnio com 69,5km². Este rio é afluente do Tapiracuí, que por sua vez é um afluente do rio Ivaí. Essa área foi escolhida por: possuir um mapeamento preexistente (EMBRAPA, 2007), com distribuição de Argissolos e Latossolos, também por estar situada em um dos sistemas pedológicos mapeados por Nakashima (1999).

Para a elaboração do mapa digital de solos, foi utilizado o Índice de Posição Topográfica (IPT) proposto por Weiss (2001), que compartimenta a vertente em regiões de terços superiores, médios ou inferiores - combinado com o índice clinografia, que caracteriza a inclinação das vertentes em grau ou porcentagem.

\section{MATERIAIS E MÉTODOS}

Com base nos dados planialtimétricos (1:50.000), disponibilizados pelo Instituto de Terras Cartografia e Geociências (ITCG), e de hidrografia, fornecidos pelo Instituto das Águas do Paraná, foi gerado o MDT para a área de estudo através do software ArcGIS 10.3. Para tanto, foi usada a ferramenta Topo to Raster (disponível no módulo Spacial Analyst tools), baseada no método de interpolação denominado Topogrid proposto por Hutchinson (1988). A resolução horizontal (tamanho de pixel) do MDT foi de uma célula de 20 metros, pautando-se no valor da equidistância das curvas de nível da base de dados altimétricos. 
O Índice de Posição Topográfica (IPT) proposto por Weiss (2001) é um atributo topográfico derivado de um algoritmo que mensura a diferença entre a elevação de um ponto central $\left(Z_{0}\right)$ e a média da elevação $(\bar{Z})$ ao seu redor (vizinhança) com um raio predeterminado $(R)$, conforme a equação 1:

$$
\mathrm{IPT}=Z_{0}-\bar{Z}
$$

Para Silveira e Silveira (2014), a análise de vizinhança pode ser feita por uma janela circular (empregada neste trabalho com o valor de 30 pixels), anelar (proposta original), retangular ou irregular. Esse procedimento metodológico foi realizado a partir da ferramenta Focal Statistics, presente também no módulo Spacial Analyst tools do software ArcGIS 10.3

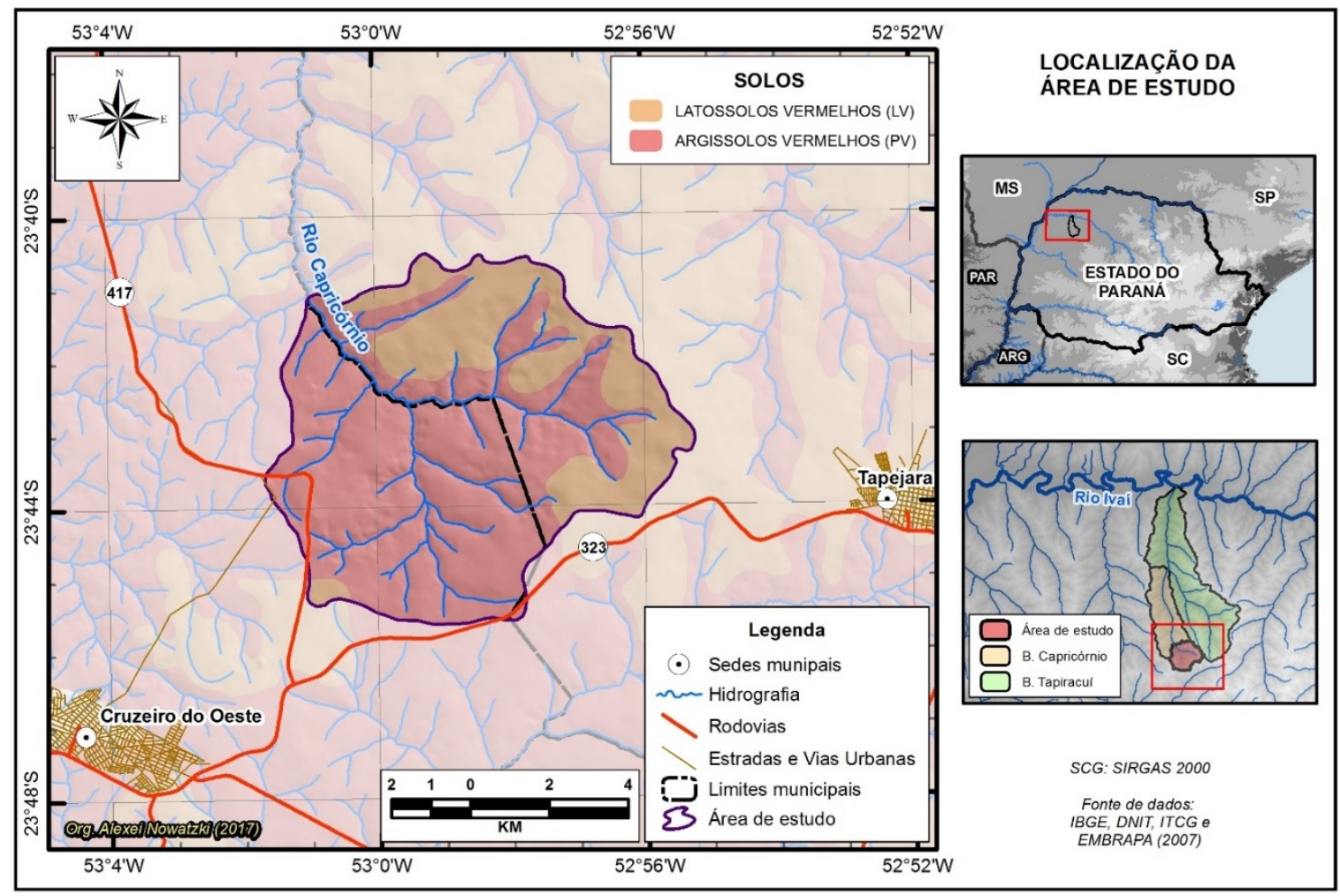

Figura 1: Localização da área de estudo (sub-bacia hidrográfica do rio Capricórnio)

Silveira (2015) destaca que os valores positivos obtidos pelo IPT representam locais que são mais elevados que a média do seu entorno, caracterizando, em geral, os divisores topográficos. Já os valores negativos representam os locais mais rebaixados em relação à sua vizinhança, caracterizando vales ou depressões. Os valores próximos a zero obtidos pelo IPT representam as superfícies de declive constante. A Figura 2 ilustra a diferença entre os valores encontrados no IPT.

Como o IPT é diretamente afetado pelo fator de escala, os valores resultantes do índice (e, consequentemente, as classificações derivadas) variam de acordo com os valores de raio adotados (SILVEIRA; SILVEIRA, 2016). A etapa de definição do raio de análise da vizinhança, portanto, deve estar associada às características físicas da área de estudo e ao nível de detalhe pretendido pelo pesquisador (DE REU et al., 2013; SILVEIRA; SILVEIRA, 2014; SILVEIRA, 2015).

De acordo com Weiss (2001) e Silveira e Silveira (2014; 2016), a discretização dos valores contínuos do IPT para a determinação de classes morfológicas pode ser feita considerando os valores de desvio padrão (DP). É considerado, portanto, o particionamento, com valores de IPT, de uma única matriz resultante. Dessa forma, propõem-se 6 classes: cristas (>1DP), vertentes superiores ( $>0,5$ e $\leq 1 \mathrm{DP})$, vertentes intermediárias $(>-0,5$ e $<-0,5 \mathrm{DP}$; declividade $<5$ graus), áreas planas $(\geq-0,5$ e $\leq-0,5 D P$; declividade $\geq 5$ graus), vertentes inferiores $(\geq-1$ e $<0,5 D P)$ e vales $(<-$ 1DP). 
Para a sub-bacia do rio Capricórnio, a discretização foi realizada com a divisão em duas classes com valores de até - 8 para a classe de IPT 1 (representando terços inferiores das vertentes) e valores acima de +8 para a classe IPT 2 (terços superiores e médios das vertentes).

Com o intuito de melhorar ainda mais a predição da distribuição dos solos na bacia em questão, foi utilizado também um atributo topográfico primário: a clinografia (MOORE et al., 1993; NOWATZKI; SANTOS, 2014). Construído a partir da análise das distâncias entre curvas de nível, esse atributo representa, de forma contínua, a inclinação e as formas do relevo (SANTOS, 2004).

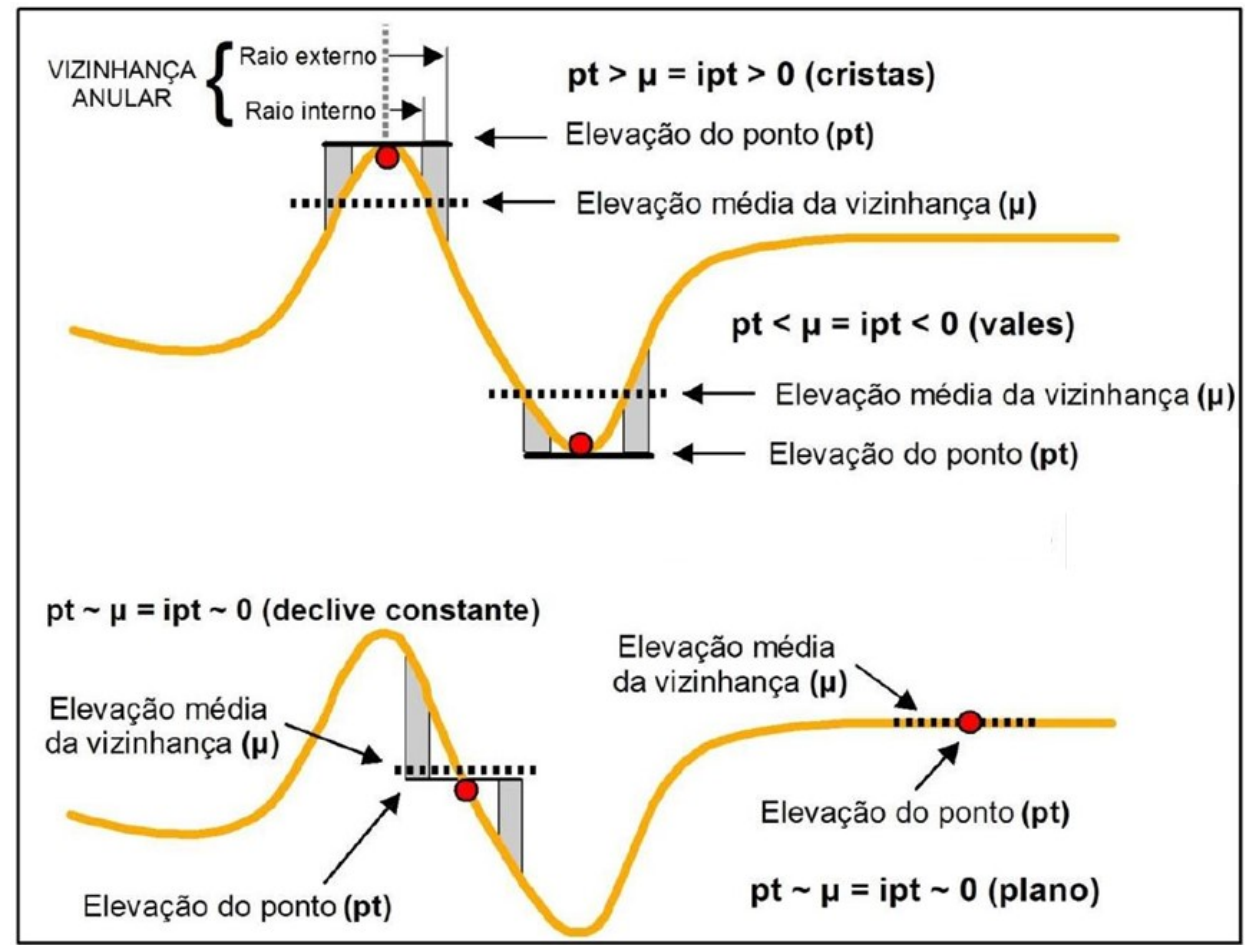

Figura 2: Índice de Posição Topográfica.

Fonte: Silveira e Silveira (2016), adaptado de Weiss (2001).

A clinografia foi determinada por duas diferenças finitas locais do MDT, nas direções $x$ e $y$, calculado pela equação 2 (HORN, 1981; SILVEIRA et al. 2012; 2013), com valor em graus:

$$
\beta=\arctan \left(\sqrt{f_{x}^{2}+f_{y}^{2}}\right)
$$

onde $\beta$ representa a inclinação local do terreno e $f_{x}^{2}$ e $f_{y}^{2}$ são definidos por aproximações das diferenças finitas por meio das derivadas parciais $f_{x}$ e $f_{y}$, nas direções de $\mathrm{x}$ e $\mathrm{y}$.

Para a representação da declividade em porcentagem $(\alpha)$, foi aplicada a equação 3 aos valores em graus de $\beta$ :

$$
\alpha=\tan \beta .(100)
$$

Para o presente trabalho foi adotada a discretização de classes com valores até $12 \%$ e acima de $12 \%$, pois, a partir desse valor, ocorre uma quebra de declive que na região noroeste pode indiciar a ocorrência de Argissolos conforme aponta Nakashima (1999). Salomão (1994) e Santos (2000) trabalharam em sistemas pedológicos semelhantes com contextos geológicos e geomorfológicos parecidos e encontraram valores similares de declividade para a ocorrência de Argissolos.

Para a integração de duas ou mais variáveis por superposição de mapas ou álgebra entre mapas, foi empregada a técnica da tabulação cruzada (TOMLIN, 1983). Essa técnica indica o conjunto de procedimentos de análise espacial em geoprocessamento que produz novos dados a partir de 
funções de manipulação aplicadas a um ou mais mapas (SILVEIRA et al., 2012; NOWATZKI, 2013; NOWATZKI; SANTOS, 2014). Neste trabalho, foi feita a tabulação entre as duas classes de IPT com as duas de clinografia, gerando quatro grupos (11, 21, 12 e 22), conforme a Tabela 1.

A partir do módulo Spacial Analyst tools do software ArcGIS 10.3 foi feita uma generalização (remoção de ruídos) dos resultados com o intuito de suprir a área mínima mapeável. A equivalência desta área no mapa, com a área correspondente no terreno, é função da escala final de apresentação. Para a escala 1:50.000 a área mínima mapeável é de 0,1 km², em acordo com IBGE (2015).

Tabela 1 - Matriz de tabulação do IPT com a clinografia

\begin{tabular}{|c|c|c|c|c|}
\hline \multirow{2}{*}{ Atributo topográfico } & \multicolumn{2}{|c|}{} & \multicolumn{2}{c|}{ Clinografia } \\
\cline { 2 - 5 } & \multicolumn{2}{|c|}{ Intervalos } & 0 a 12 & 12 a 36 \\
\cline { 2 - 5 } & & Classe & 1 & 2 \\
\hline \multirow{2}{*}{ IPT } & -32 a -8 & 1 & $\mathbf{1 1}$ & $\mathbf{2 1}$ \\
\cline { 2 - 5 } & -8 a 21 & 2 & $\mathbf{1 2}$ & $\mathbf{2 2}$ \\
\hline
\end{tabular}

Para validar os resultados encontrados pelo MDS, foi realizada - em uma vertente que representasse a transição lateral Latossolo-Argissolo - uma investigação em topossequências (BOULET et al., 1982), ou seja, uma transeção do topo até a base da vertente, por meio de sondagens com trado holandês (Figura 3). Foram percorridos aproximados 800 metros e feitas oito investigações.

Seguindo as especificações de caracterização analítica e determinações de campo indicadas de EMBRAPA (2013) e IBGE (2015), foram analisadas as seguintes características morfológicas do solo: transição entre horizontes; profundidade e espessura dos horizontes; cor; e textura. Todas as amostras de solo analisadas foram coletadas e armazenadas em um pedocomparador.

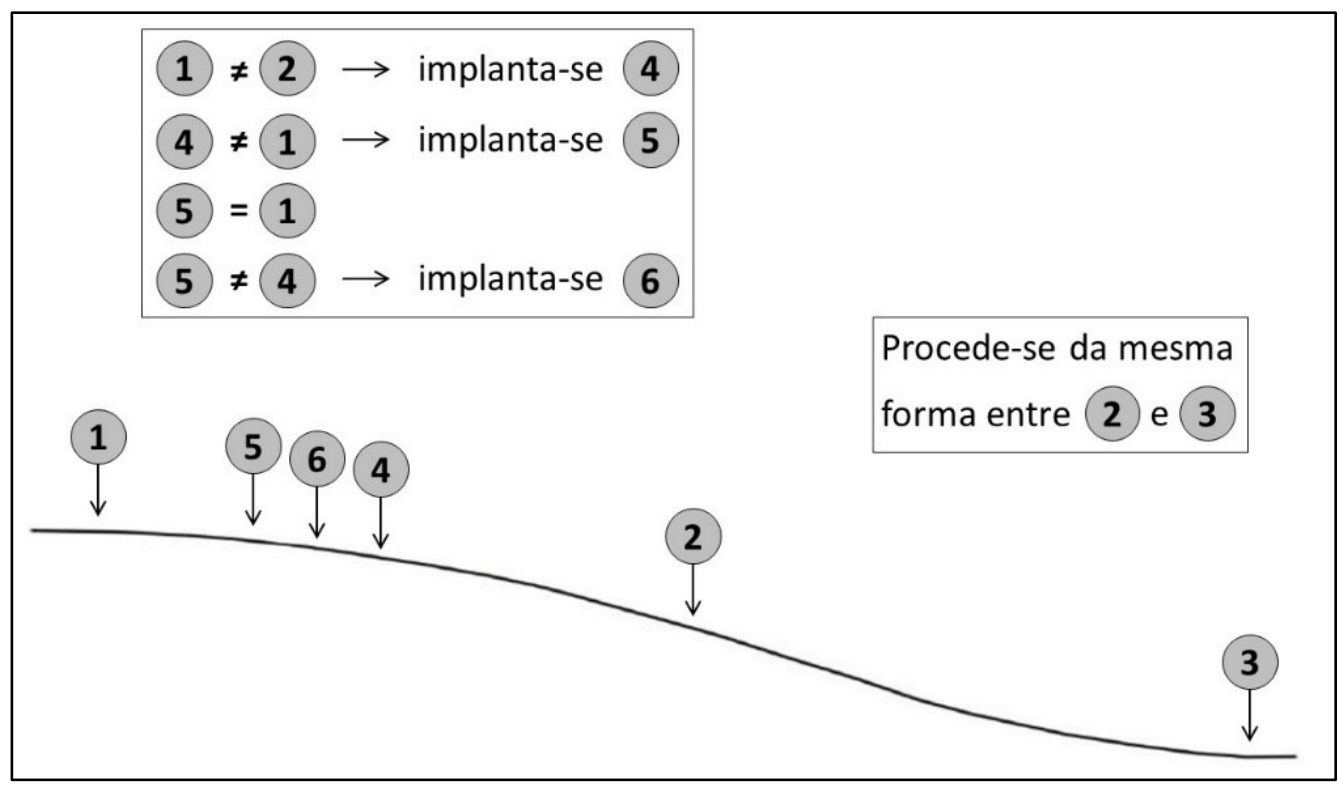

Figura 3: Método de investigação em topossequência. Fonte: Adaptado de Boulet et al. (1982) 


\section{RESULTADOS E DISCUSSÕES}

A partir da discretização dos atributos IPT e clinografia, foram mapeadas duas classes para ambos os atributos (Figura 4). Os valores do IPT encontram-se entre -32 e 21 e a média em 0,2. Isso comprova a homogeneidade do relevo, pois, de acordo com a metodologia, os valores próximos de zero constituem áreas com declives constantes e, nesse caso, mais suavizadas. Os valores de IPT entre -8 e -32 (classe 1) representam as porções de terço inferior das vertentes, onde localizam-se grande parte dos Argissolos da região, conforme foi destacado por Nakashima (1999). Essas porções se situam nos fundos de vales e tiveram uma distribuição maior ou menor, de acordo com a topografia da vertente. Os demais valores (classe 2), entre -8 e 21 , representam as áreas de provável ocorrência dos Latossolos.

A discretização da clinografia, por sua vez, foi marcada por valores de $0 \%$ a $12 \%$ (classe 1 ), para os Latossolos. Já a espacialização da classe 2 ocorre nas áreas mais declivosas da sub-bacia ( $12 \%$ e $36 \%$ ), que se distribuem nas proximidades dos terços inferiores das vertentes, locais onde há uma pequena quebra de declive. Ao longo da sub-bacia, a média geral da clinografia é de $8 \%$, característica de relevos planos ou suave ondulados.

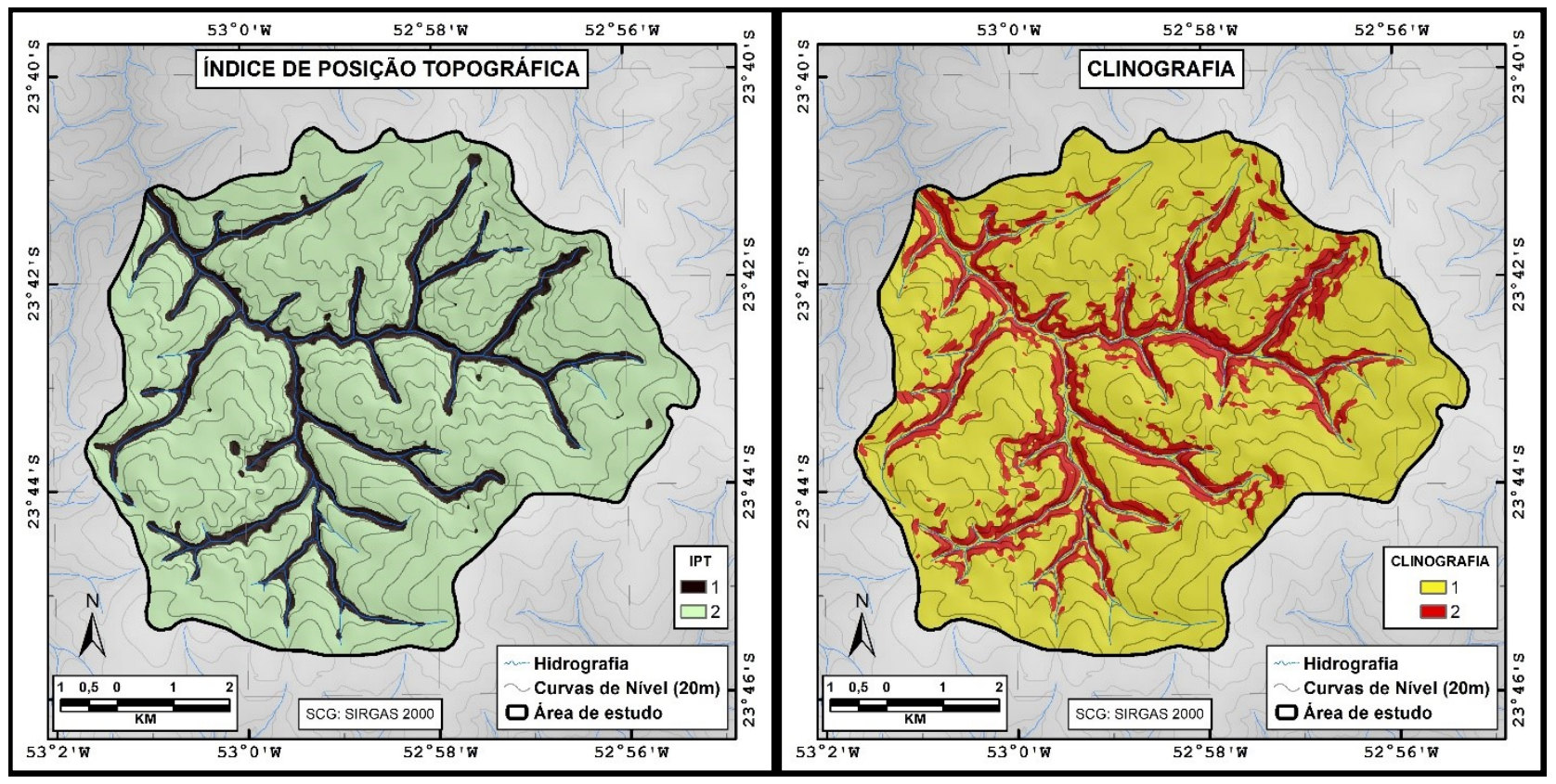

Figura 4: Atributos topográficos da área de estudo

A partir desse resultado, pode-se evidenciar que há uma superestimação da classe de Argissolos no mapeamento de solos da EMBRAPA (2007), pois tanto o atributo IPT quanto o clinografia destacam o quanto as características morfológicas da região noroeste influenciam na distribuição dos Argissolos, evidenciando dessa maneira o ganho de informações que o uso de uma base de dados mais detalhada pode fornecer em um mapeamento pedológico preditivo.

Tendo como base os dois atributos supramencionados, foi feita a matriz de tabulação cruzada, que apresentou quatro classes. Em seguida, essa matriz foi agrupada em três grupos de predição de ocorrência de classes de solos, conforme a Figura 5.

Conforme a matriz de tabulação, as combinações 11 e 21 resultaram no grupo 1, que se refere à distribuição dos Argissolos da bacia, os quais ocuparam $14,7 \%$ do total da área. A combinação 12 representou os Latossolos, estendendo-se pela maior parte da bacia, com 76,1\%. Por fim, a combinação 22 foi enquadrada no grupo 3 , que se refere a porções com solos de transição de Latossolos para Argissolos, ocupando 9,2 \%.

De acordo o mapeamento de EMBRAPA (2007), na área (Figura 1) são encontrados, no primeiro nível categórico da classificação brasileira de solos (EMBRAPA, 2013): Latossolos (L) - em 27,8 \% da área - e Argissolos $(P)$ - em 72,2 \%. Isso demonstra que nesse mapeamento há uma 
superestimação de Argissolos na área, pois, tanto com base nos elementos de reconhecimento de campo quanto na classificação digital, os Latossolos ocorrem na maior parte da área estudada.

A Figura 6 ilustra a disposição das oito tradagens ao longo da vertente, bem como a distribuição dos grupos gerados pelo mapeamento digital de solos nesta porção da bacia.

Os resultados de campos apresentaram que partindo do terço superior da vertente verificada, as quatro primeiras mostraram a ocorrência de Latossolos, informações essas coerentes com o mapeamento digital realizado.

A partir da quarta tradagem, observou-se em campo um incremento de argila no horizonte B, porém insuficiente para diagnosticar a presença de um horizonte B textural, característico dos Argissolos. Contudo, no mapa digital de solos essa tradagem já aparece no grupo dos Argissolos.

De acordo com a caracterização morfológica realizada em campo, os três últimos pontos (terço inferior da vertente) apontaram a ocorrência de Argissolos, pois foi encontrado um incremento de argila no horizonte $\mathrm{B}$, logo abaixo de um horizonte superficial bastante arenoso. $\mathrm{O}$ intuito dessas observações foi demonstrar que é preciso ter pelo menos um controle de campo para que o MDS possa ter maior confiabilidade.

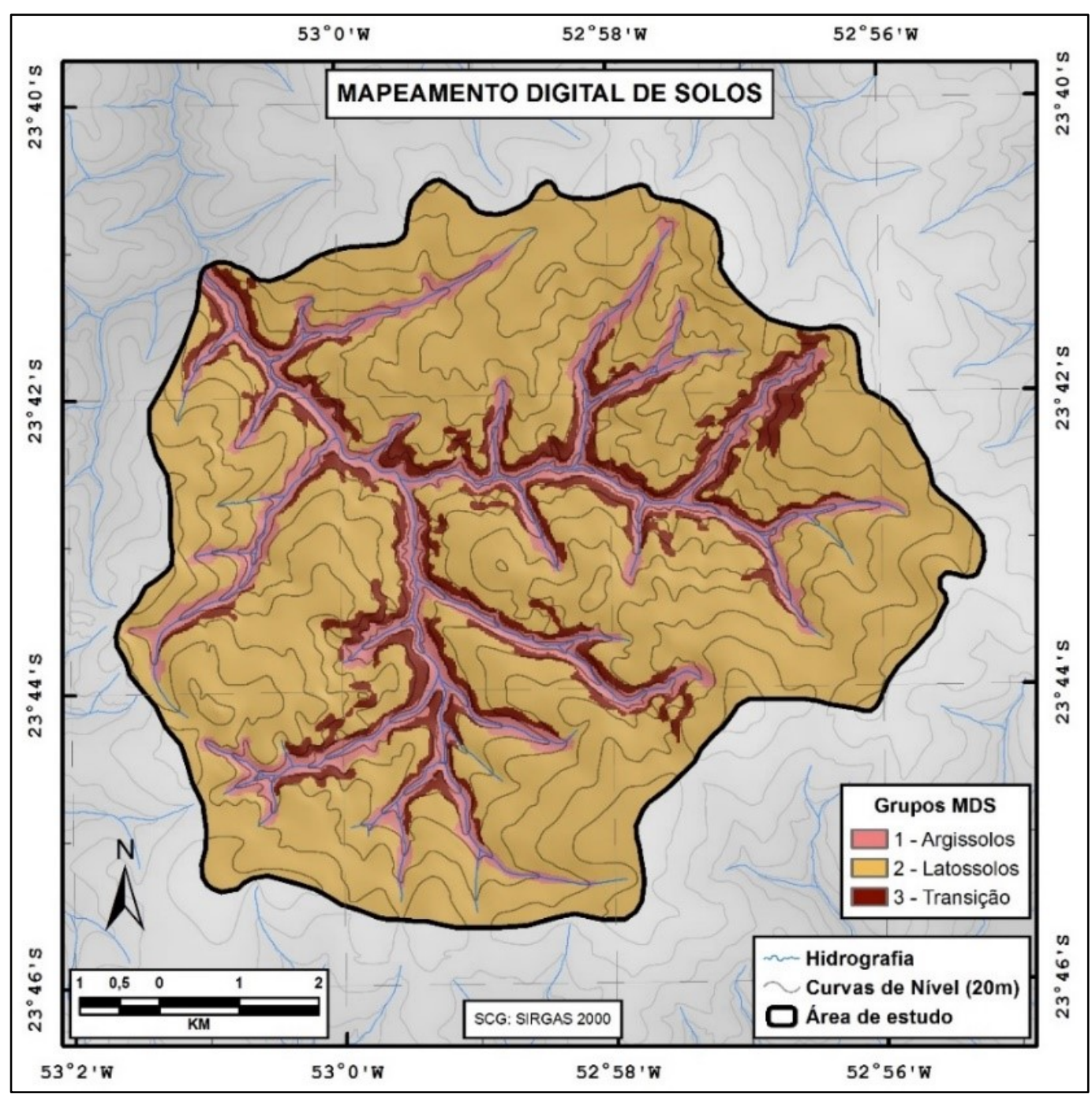

Figura 5: Grupos de solos preditos pelo MDS da área de estudo 


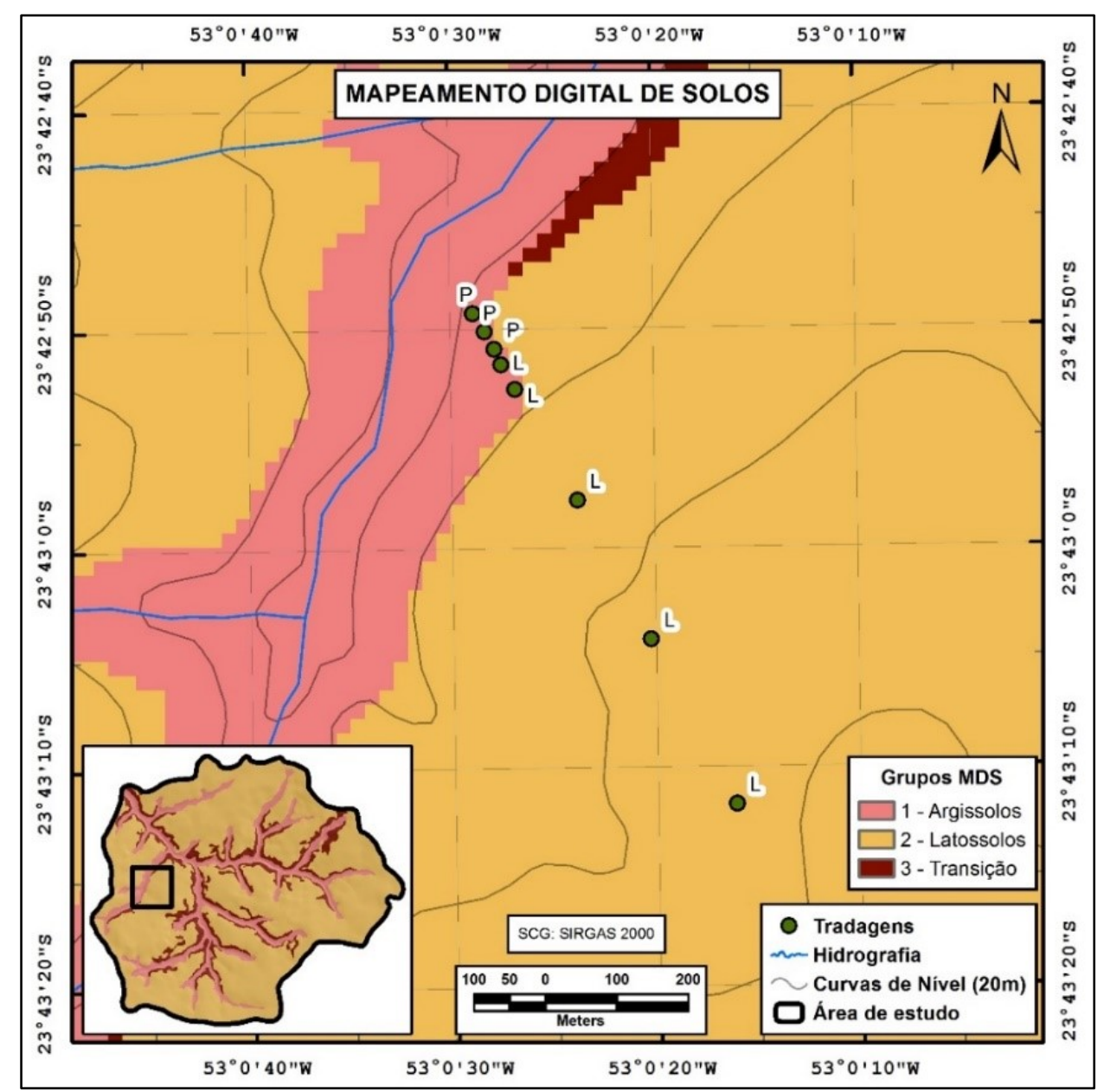

Figura 6: Tradagens realizadas na área de estudo e os grupos gerados pelo MDS.

Legenda: Latossolos $=\mathrm{L}$ e Argissolos $=\mathrm{P}$

\section{CONCLUSÕES}

A partir dos resultados apresentados pelo mapeamento digital de solos, juntamente com a verificação de campo, pode-se concluir que foi possível estabelecer regras para a combinação entre o índice de posição topográfica com a clinografia, cujo resultado se apresentou satisfatório para representação cartográfica, na escala 1:50.000, da distribuição dos Latossolos e dos Argissolos na área de estudo em questão.

Muito embora os valores utilizados na discretização desse experimento tenham expressado satisfatoriamente a diferenciação entre os dois solos em questão, eles não podem ser generalizados para toda a extensão do noroeste paranaense, pois, mesmo com a homogeneidade do relevo, existem distintos sistemas pedológicos na região, com vertentes de diferentes características. Isso faz com que o mapeamento digital de solos deva ser testado para cada um desses sistemas.

Com base na análise dos mapeamentos pedológicos preexistentes, pode-se afirmar que existe uma superestimação na representação espacial dos Argissolos ao longo da área de estudo, averiguado tanto nos resultados do mapeamento digital quanto na verificação de campo. Ainda foi observado que a ocorrência dos Argissolos está restrita nas posições dos terços inferiores das vertentes. 


\section{REFERÊNCIAS}

BOULET, R.; CHAUVEL, A.; HUMBEL, F. X.; LUCAS, Y. Analyse estructurale et cartographie en pedologie. I - Prise en compte l'organisation bidimensionalle de la couverture pédologique: les étude de toposéquenses et leurs principaux apport à la connaissance des sols. Cah. Orstom. Paris, França. Série Pédologie. v. XIX, n. 4. p. 309-322. 1982

COELHO, F. F. Comparação de métodos de mapeamento digital de solos através de variáveis geomorfométricas e sistemas de informações geográficas. Porto Alegre, $80 \mathrm{f}$. Dissertação (Mestrado em Sensoriamento Remoto). Programa de pós-graduação em Sensoriamento Remoto. Centro estadual de pesquisas em Sensoriamento Remoto e Meteorologia. Universidade Federal do Rio Grande do Sul, 2010.

DALMOLIN, R. S. D. e TEN CATEN, A. Mapeamento Digital: nova abordagem em levantamento de solos. Investigación Agraria, v. 17, p. 77-86, 2015.

DE REU, J.; BOURGEOISA, J.; BATSA, M.; ZWERTVAEGHERB, A.; GELORINIB, V.; SMEDTC, P.; CHUE, W.; ANTROPD, M.; MAEYERD, P.; FINKEB, P.; MEIRVENNEC, M.; VERNIERSB, J.; CROMBÉA, P. Application of the topographic position index to heterogeneous landscapes. Geomorphology, n. 186, p. 39-49, 2013.),

EMBRAPA (Empresa Brasileira de Pesquisa Agropecuária). Sistema Brasileiro de Classificação de Solos. Centro Nacional de Pesquisa de Solos. 3. Ed. Rio de Janeiro: Embrapa Solos, 2013.

EMBRAPA (Empresa Brasileira de Pesquisa Agropecuária) Mapa de Solos do Estado do Paraná Escala 1:250.000. Rio de Janeiro: Embrapa Solos, 2007.

FERNANDES, L.A.; COUTO, E.V.; SANTOS, L.J.C. Três Morrinhos, Terra Rica, PR Arenitos silicificados de dunas do Deserto Caiuá testemunham nível de superfície de aplainamento K-T. In: WINGE, M. et al (edit./org.). Sítios geológicos e paleontológicos do Brasil, vol. III. Brasília. Serviço Geológico do Brasil - CPRM, 2012, v. III, p. 69-87.

GASPARETTO, N.V.L.; NÓBREGA, M.T. E CARVALHO, A. A reorganização da cobertura pedológica no noroeste do Paraná e as suas relações com o Arenito Caiuá. In: Encuentro de Geografos de America Latina, 8., 2001, CDRom,Santiago, EGAL. 2001. p. 164 -169.

HORN, B. K. P. Hill shading and the reflectance map. Proceedings of the IEEE, n. 69, v. 01, p. 1447, 1981.

HUTCHINSON, M. F. Calculation of hydrologically sound digital elevation models. Paper presented at Third International Symposium on Spatial Data Handling at Sydney, Australia, 1988.

INSTITUTO BRASILEIRO DE GEOGRAFIA E ESTATÍSTICA (IBGE). Coordenação de Recursos Naturais e Estudos Ambientais. Manual técnico de pedologia. 3. ed. Rio de Janeiro, 430 p. 2015

LAGACHERIE, P.; VOLTZ, M. Predicting soil properties over a region using sample information from a mapped reference area and digital elevation data: a conditional probability approach. Geoderma. v.97, p. 187-208, 2000.

LAGACHERIE, P. Digital Soil Mapping: A State of art. In.: HARTEMINK, A.E.; McBATNEY, A.; MENDONÇA-SANTOS, M. DE L. (Ed.), Digital Soil Mapping with Limited Data. New York: Springer, 2008, p.3-14

MANGUEIRA, C. G.; COUTO, E. V.; SANTOS, L. J. C. Relação solo e relevo na distribuição de formas erosivas no noroeste do Paraná - Brasil. In: VI Congresso Nacional de Geomorfologia, 2013, Coimbra - PT. VI Congresso Nacional de Geomorfologia: Atas- Proceedings, 2013. v. 1. p. 41-44

McBRATNEY, A.B.; ODEH, I.O.A.; BISHOP, T.F.A.; DUNBAR, M.S.; SHATAR, T.M. An overview of pedometric techniques for use in soil survey. Geoderma, v. 97, n. 3-4, p.293-327, 2000.

McBRATNEY, A.B.; MENDONÇA-SANTOS, M.L.; MINASNY, B. On digital soil mapping. Geoderma, v. 117, p. 3-52, 2003.

MOORE, I.D.; GESSLER, P.E.; NIELSEN, G.A.; PETERSON, G.A. Soil attribute prediction using terrain analysis. Soil Science Society American Journal. v. 57, p. 443-452, 1993 
NAKASHIMA, P. Sistemas pedológicos da região noroeste do Estado do Paraná: distribuição e subsídios para o controle da erosão. São Paulo, Tese (Doutorado em Geografia Física) Faculdade de Filosofia, Letras e Ciências Humanas, Universidade de São Paulo, 1999.

NOWATZKI, A. Utilização de atributos topográficos no mapeamento preliminar de solos da bacia hidrográfica do rio Pequeno (Antonina/PR). Dissertação (Mestrado em Análise Ambiental e da Paisagem, Geografia). Universidade Federal do Paraná. Curitiba, 2013.

NOWATZKI, A.; SANTOS, L. J. C. Mapeamento preliminar de solos por pedometria com base em atributos topográficos da bacia hidrográfica do rio Pequeno-PR. RA'E GA: o Espaço Geográfico em Análise, v. 32, p. 185-211, 2014.

SALOMÃO, F.X.T. Processos erosivos lineares em Bauru: regionalização cartográfica aplicada ao controle preventivo urbano e rural. São Paulo, 1994. 200 p. Tese (Doutorado em Geografia Física) - Departamento de Geografia da FFLCH, Universidade de São Paulo.

SANTOS, L. J. C. Pedogênese no topo do platô de Bauru (SP): o caso da Bacia do Córrego da Ponte Preta São Paulo: FFLCH-USP, 2000. 186f. Tese (Doutorado em Geografia) - Programa de Pós-Graduação em Geografia, Universidade de São Paulo.

SANTOS, L. J. C; WESTPHALEN, L. A. Erosão dos Solos no noroeste do Paraná. In: GUERRA, A. J. T; OLIVEIRA, M. C. Degradação dos solos no Brasil. Rio de Janeiro: Bertrand Brasil, 2014, p.293-317, 2014.

SANTOS, R. F. Planejamento ambiental: teoria e prática. São Paulo: Oficina de Textos, 2004

SILVEIRA, R. M P. Análise digital do relevo como apoio para a cartografia geomorfológica da porção central da Serra do Mar Paranaense. Dissertação (Mestrado em Paisagem e Análise Ambiental, Geografia). Universidade Federal do Paraná. Curitiba, 2015.

SILVEIRA, C. T. Análise digital do relevo na predição de unidades preliminares de mapeamento de solos: Integração de atributos topográficos em Sistemas de Informações Geográficas e redes neurais artificiais. Curitiba, 2010, $153 \mathrm{f}$. Tese (Doutorado em Geografia). Departamento de Geografia, Setor de Ciências da Terra, Universidade Federal do Paraná.

SILVEIRA, C.T.; OKA-FIORI, C.; SANTOS, L.J.C.; SIRTOLI, A.V.; SILVA, C.R. Pedometria apoiada em atributos topográficos com operações de tabulação cruzada por álgebra de mapas. Revista Brasileira de Geomorfologia. Vol. 13, n 2. 2012.

SILVEIRA, C. T. OKA-FIORI, C.; SANTOS, L. J. C; SIRTOLI, A. E.; SILVA, C. R.; BOTELHO, M. F. Soil prediction using artifi cial neural networks and topographic attributes. Revista Geoderma 195-196, p. 165-172, 2013.

SILVEIRA, R. M. P.; SILVEIRA, C. T. Classificação morfológica obtida pelo Índice de Posição Topográfica na região central da Serra do Mar paranaense. In: X Simpósio Nacional de Geomorfologia (10 SINAGEO), 2014, Manaus. Anais do X Simpósio Nacional de Geomorfologia (10 SINAGEO), 2014.

SILVEIRA, R. M. P.; SILVEIRA, C. T. Análise digital do relevo aplicada à cartografia geomorfológica da porção central da Serra do Mar Paranaense. Revista Brasileira de Geomorfologia , v. 17, $\mathrm{n}^{\circ}$ 4, 615-629, 2016.

SIRTOLI, A. E.; SILVEIRA, C. T.; MONTOVANI, L. E.; SIRTOLI, A. R. A.; OKA-FIORI, C. Atributos do relevo derivados de modelo digital de elevação e suas relações com solos. Scientia agraria, v.9, n.3, p.317-329, 2008.

TESKE, R.; GIASSON, E.; BAGATINI, T. Produção de um mapa pedológico associando técnicas comuns aos mapeamentos digitais de solos com delineamento manual de unidades de mapeamento. Rev. Bras. Ciênc. Solo, Viçosa, v. 39, n. 4, p. 950-959, 2015.

TOMLIN, C. D. A Map Algebra. In Proceedings of Harvard Computer Graphics Conference, at Cambridge, Mass, 1983.

WEISS, A. Topographic Position and Landforms Analysis. Poster presentation, ESRI User Conference, San Diego, CA, 2001. 